\title{
REMEDIOS OFTÁLMICOS EN LA MATERIA MÉDICA DE DIOSCÓRIDES (III)
}

\author{
LÓPEZ DE LETONA C ${ }^{1}$
}

Las propiedades curativas de raíces, zumos, hierbas y simientes domésticas ordinarias, constituyen el contenido del libro tercero de la materia médica de Pedacio Dioscórides Anazarbeo, en su traducción de Andrés Laguna que estamos comentando.

Como en otras ocasiones el número de especímenes curativos es escaso, no pasa de los nueve, algunos como el hysopo si se introduce en agua hirviendo es capaz de disolver «Los cardenales que se engendran en los ojos» otros como el eneldo (planta aromática utilizada incluso en los tiempos actuales en determinados condimentos) «Embota la vista».

Por su parte el zumo de raíz de romero puede mezclarse con miel para aguzar y clarificar la visión.

En la versión que hemos manejado se habla también de una especie vegetal que crece en las regiones el norte de África y que la denomina agasillys o amoníaco cuyo licor destilado resuelve las motas que perturban la vista extirpando también las asperezas que suelen formarse en los párpados.

Se cita también otra especie vegetal cuyo nombre puede inducir a equivocación, se la denomina blepharon, este término guarda relación con los párpados, pero en realidad no tiene nada que ver con ellos por que su flor, que es una rosa, si se machaca mezclada con vino negro puede poseer determinadas propiedades afrodisíacas.

Habla más adelante del marrubio, planta que crece en los muladares y en las ruinas de los edificios su zumo incorporado con vino y miel «esclarece la vista», como en el caso citado antes sus hojas, que son muy pequeñas casi del tamaño de una pulga «reprimen las uñas que se forman en los ojos».

Finalmente las flores del lirio salvaje «Relajan las inflamaciones de los ojos».

El siguiente libro, es decir el cuarto, viene a ser «un cajón de sastre» que se enuncia de esta forma: «Resto de las raíces y plantas que restan».
Tampoco aquí se recogen demasiadas especies con propiedades curativas oftalmológicas, no llegan a las diez.

Comienza con el erino, en la denominación moderna albahaca; afirma lo siguiente: «Mezcladas dos dracmas de su simiente con cuatro cyatos de miel e instilado en los ojos reprimen los humores que corren a ellos».

Vayamos por partes: la expresión «Humores que corren a ellos» puede referirse bien a una secreción lagrimal excesiva o a una conjuntivitis, sin dar más datos de su posible etnología (porque podría haberse fijado si hay más humores en verano o primavera, lo que pudiese indicar una causa alérgica).

Por otra parte el asunto de las medidas señaladas es algo difícil de exponer, el mismo Andrés Laguna nos indica en un apéndice de su traducción que la dracma griega contiene a su vez tres escrúpulos y cada uno de estos veinte granos de modo que la dracma no sería una medida de volumen tan pequeña como podríamos imaginarnos.

Es posible que con esta última expresión se esté refiriendo a las legañas.

Se hace también referencia a otra especie identificada con el opio y que se recoge bajo el nombre de papaver del que distingue dos variantes: doméstico y cornudo. El primero de ellos se puede identificar con la amapola. Ofrece la siguiente receta: «Aplicada con una yema de huevo asada y con el mismo azafrán aprovecha mucho a las inflamaciones de los ojos».

Por su parte el papaver cornudo sus hojas y sus flores pueden mezclarse con aceite en forma de emplasto que aplicado en los ojos de las bestias de carga «les resuelve las nubes».

Debemos tener siempre en cuenta las propiedades deletereas del opio, señalando también la adicción a esta droga conocida desde la antigüedad que incluso dio lugar a conflictos bélicos, sin embargo

${ }^{1}$ IOBA. Valladolid. España.

E-mail: berta@ioba.med.uva.es 
en la obra que estamos comentando no se recoge ninguno de estos aspectos.

Las fístulas lagrimales se pueden curar mediante las hojas machucadas de la solano hortense.

¿Qué idea podían tener de las fístulas lagrimales?, sabemos que eran conocidas desde la antigüedad, acaso se tratase también de una nota marginal introducida por el traductor.

Hay que referirse también a la mandrágora, planta casi mitológica por los efectos de sus raíces, curiosamente podía causar la muerte a la persona que la extrajese de la tierra y por ello, según un artículo que hemos consultado, se recurría a perros amaestrados para su extracción.

En nuestro caso particular la mandrágora «Suele mezclarse en las medicinas para los ojos».

Citemos otro veneno, nada menos que la cicuta, tóxico mortal muy utilizado en la época de nuestro autor. Es una planta umbelífera de tallo rojizo que mide unos dos metros de alto con hojas blandas verdinegras y fétidas divididas en gajos puntiagudos.

También servía claro está para mitigar las molestias oculares.

En el libro quinto se apuntan algunas referencias curativas de los vinos y de los minerales.

El fruto de la vid silvestre «Cuando está en flor» es el enathene, útil para las referidas fístulas: debe majarse con azafrán, mirra, y aceite rosado. Sus cenizas pueden también usarse como vehículo de determinadas medicinas oculares.

Caso parecido es el del agraz que viene a ser la uva immadura.

Finalmente el vinagre es decir el producto de la fermentación ácida del vino (ácido acético y agua) es capaz también de aguzar la visión. 